\title{
The Relationship between Socio demographic Factors and Terminated Pregnancy among Nigerian Women
}

\author{
Samuel Adewale Aderoju \\ Department of Statistics and Mathematical Sciences, Kwara State University, Malete, P.M.B. 1530, Ilorin, Kwara State, Nigeria. \\ E-mail: samuel.aderoju@kwasu.edu.ng
}

Correspondence Author: Samuel Adewale Aderoju, Department of Statistics and Mathematical Sciences, Kwara State University, Malete, P.M.B. 1530, Ilorin, Kwara State, Nigeria.

E-mail: samuel.aderoju@kwasu.edu.ng

Received date: 15 September 2019, Accepted date: 12 December 2019, Online date: 31 December 2019

Copyright: () 2019 Samuel Adewale Aderoju, This is an open-access article distributed under the terms of the Creative Commons Attribution License, which permits unrestricted use, distribution, and reproduction in any medium, provided the original author and source are credited.

\begin{abstract}
Background: Pregnancy termination is an illegal medical procedure in Nigeria except in a situation of having the child puts the mother's life at risk. Hence, the act is a rare event in the country and associated with some sociodemographic factors.

Objective: The aims of the study were to appropriately model pregnancy termination so as to evaluate sociodemographic factors contributing to having terminated pregnancy among Nigerian women.

Methods: The data were extracted from the 2013 Nigeria Demographic and Health Survey (NDHS) which exhibited class imbalanced, hence, logistic regression in large rare events and imbalanced data using different resampling techniques were exploited to improve the model's performance. Synthetic Minority Oversampling Technique (SMOTE) function was used to improve the model's performance. The analysis was done using $R$ software.

Results: The results showed that the model's sensitivity and Precision values improved from zero to $50 \%$ and $32.43 \%$ respectively; this aspect is missing in the previous literatures to the best of my knowledge. Keeping other factors constant, a unit increase in age the odds of having pregnancy termination increases by $3.6 \%$; women living in urban area were $50 \%$ more likely to experience pregnancy termination than women living in rural area; women from North East (NE), North West (NW), South East (SE), South South (SS) and South West (SW) were 83.5\%, 22.5\%, $43.2 \%, 25.3 \%$ and $25.9 \%$, respectively, more likely to experience pregnancy termination than women from North Central (NC); women with primary, secondary and higher education levels were $39.2 \%, 50.1 \%$ and $44 \%$, respectively, more likely to experience pregnancy termination compared to women with no education.

Conclusion: The findings of this study shows that in using predictive model, there is need to evaluate the model's accuracy, sensitivity and precision in order to ascertain the reliability of the model's results. Moreover, family planning projects in Nigeria should stress on advancing the use of modern preventative techniques to further reduce the cases of pregnancy termination. Above all, there is need to improve maternal healthcare services in order to help women during the difficulties of unintended pregnancy.
\end{abstract}

Keywords: terminated pregnancy, sociodemographic factors, logistic regression, sensitivity, resampling techniques

\section{INTRODUCTION}

Health matter in the world is a significant concern to everyone and Nigeria's case is not different. Over the years, the Nigerian government and every health stakeholder have been working on improving the health and well-being of the country. Pregnancy termination is unlawful in Nigeria except it is performed to save the life of the pregnant woman. However, pregnancy termination continues to be carried out, sometimes with awful consequences for the lives and health of the women involved. There are socio-demographic factors that are associated with pregnancy termination. The termination or expulsion of an unintended pregnancy, which is induced abortion, is a collective gynecological experience across the world (Appiah-Agyekum, 2014; Singh, 2017). Over the period between 2010 and 2014, an estimated fifty-six million induced abortions occurred. This put the annual rate to be thirty-five induced terminated pregnancies per 1,000 women aged 15 to 49 years. Regional incidence data suggest that developing countries in Africa, Asia and Latin America accounted for the majority, but at about 49.3 million, of this total annual global abortion rate (Singh, 2017; Ganatra, 2017). 
The majority of the abortions in Nigeria are being committed in secrecy by the "quack doctors" (that is, incompetent professional) in very untidy environments due to the desperation of the clients and the need to make easy money by the doctors (Ordinioha, 2008). This situation has in no doubt contributed to the increasing prevalence of unsafe abortion resulting in increasing maternal mortality rate, with up to $40 \%$ maternal deaths in Nigeria due to induced abortion (WHO, 2018; Ordinioha, 2008). Yaya et al., (2018) discovered that the overall prevalence of pregnancy termination and unintended pregnancy were about $11 \%$ in Nigeria. To the best of my knowledge, the existing works of literature did not report the accuracy, sensitivity and precision of the model let alone improving them. This is one significant contribution to this study. The main objective of this study is to accurately determine the socio-demographic factors associated with abortion among Nigeria women of reproductive age with improved model accuracy, sensitivity and precision.

The paper is organized as follows: section 2 contains materials and methods. The results are presented in Section 3 . A discussion of the results is given in section 4, while the conclusion and recommendation are presented in section 5.

\section{MATERIALS AND METHODS}

\section{Study Data}

This study used data from the 2013 Nigeria Demographic and Health Survey, NDHS, (NPC and ICF, 2014). The sample for the data covered the entire population residing in non-institutional dwelling units in the country. The survey used as a sampling frame, the list of enumeration areas (EAs) prepared for the 2006 Population Census of the Federal Republic of Nigeria, provided by the National Population Commission. The sample was designed to provide population and health indicator estimates at the national, zonal, and state levels.

The data comprises of 27,440 observations with eight variables. The summary of the variables is presented in Table 1 . The female respondents of ages ranging between 15 - 49 years were interviewed. Of the 27,440 respondents, 3616 (13.18\%) reported "Yes" and $23824(86.82 \%)$ reported "No" to ever having terminated a pregnancy (Figure 1). So as to better evaluate the factors associated with pregnancy termination, sociodemographic factors including age, age at first birth, region, place of residence, highest education level and financial status of the respondents were extracted from the data (as shown in Table 1).

Table 1: Summary of study variables used in the study

\begin{tabular}{|c|c|c|c|}
\hline Variable name & Description & Coding structure & Count \\
\hline Pregnancy Termination & Ever had a pregnancy terminated? & $\begin{array}{l}\text { No }=0 \\
\text { Yes }=1\end{array}$ & $\begin{array}{l}\text { No }=23824(86.82 \%) \\
\text { Yes }=3616(13.18 \%)\end{array}$ \\
\hline Age & Age of the respondents & Ranging from $15-49$ years & \\
\hline Region & Geo-political zone & $\begin{array}{c}\text { North Central (NC) } \\
\text { North East (NE) } \\
\text { North West (NW) } \\
\text { South East (SE) } \\
\text { South South (SS) } \\
\text { South West (SW) }\end{array}$ & $\begin{array}{c}\mathrm{NC}=4188 \\
\mathrm{NE}=5094 \\
\mathrm{NW}=7726 \\
\mathrm{SE}=2621 \\
\mathrm{SS}=3827 \\
\mathrm{SW}=3984\end{array}$ \\
\hline Residence & Place of residence & $\begin{array}{l}\text { Rural } \\
\text { Urban }\end{array}$ & $\begin{array}{l}\text { Rural: } 17663 \\
\text { Urban: } 9777\end{array}$ \\
\hline Education & Highest education level & $\begin{array}{c}\text { No Education } \\
\text { Primary } \\
\text { Secondary } \\
\text { Higher }\end{array}$ & $\begin{array}{c}11946 \\
5950 \\
7473 \\
2071\end{array}$ \\
\hline Wealth & The financial status of the respondents & $\begin{array}{c}\text { Poor } \\
\text { Middle } \\
\text { Rich }\end{array}$ & $\begin{array}{c}11370 \\
5587 \\
10483 \\
\end{array}$ \\
\hline Age at first birth & Respondent's age at first childbirth & Ranging from $12-45$ years & \\
\hline
\end{tabular}

Source: 2013 NDHS

\section{Variables}

Pregnancy termination is the outcome variable which is dichotomous ('Yes' or 'No'). The explanatory variables are the age of the respondents, Geo-political zone (region), place of residence, highest education level, the financial status of the respondents and their ages at first birth. Age is a numerical variable while others are categorical variables.

\section{Data Analysis}

All statistical analysis was performed using R version 3.5.2 (R Core Team, 2018) applying a logistic regression model. The two classes in the outcome variable are heavily imbalance, that is, a class is highly greater than the other class. Majority of women ('No' $=86.81 \%$ ) had never experienced pregnancy termination while minority class ('Yes' = 13.19\%) had ever experienced pregnancy termination (Figure 1). Hence, some resampling techniques were applied using 'ROSE' and 'caret' packages in R (Lunardon and Nicola, 2014; Kuhn et al., 2018) to improve the model's sensitivity and precision, which were initially zero percent. 


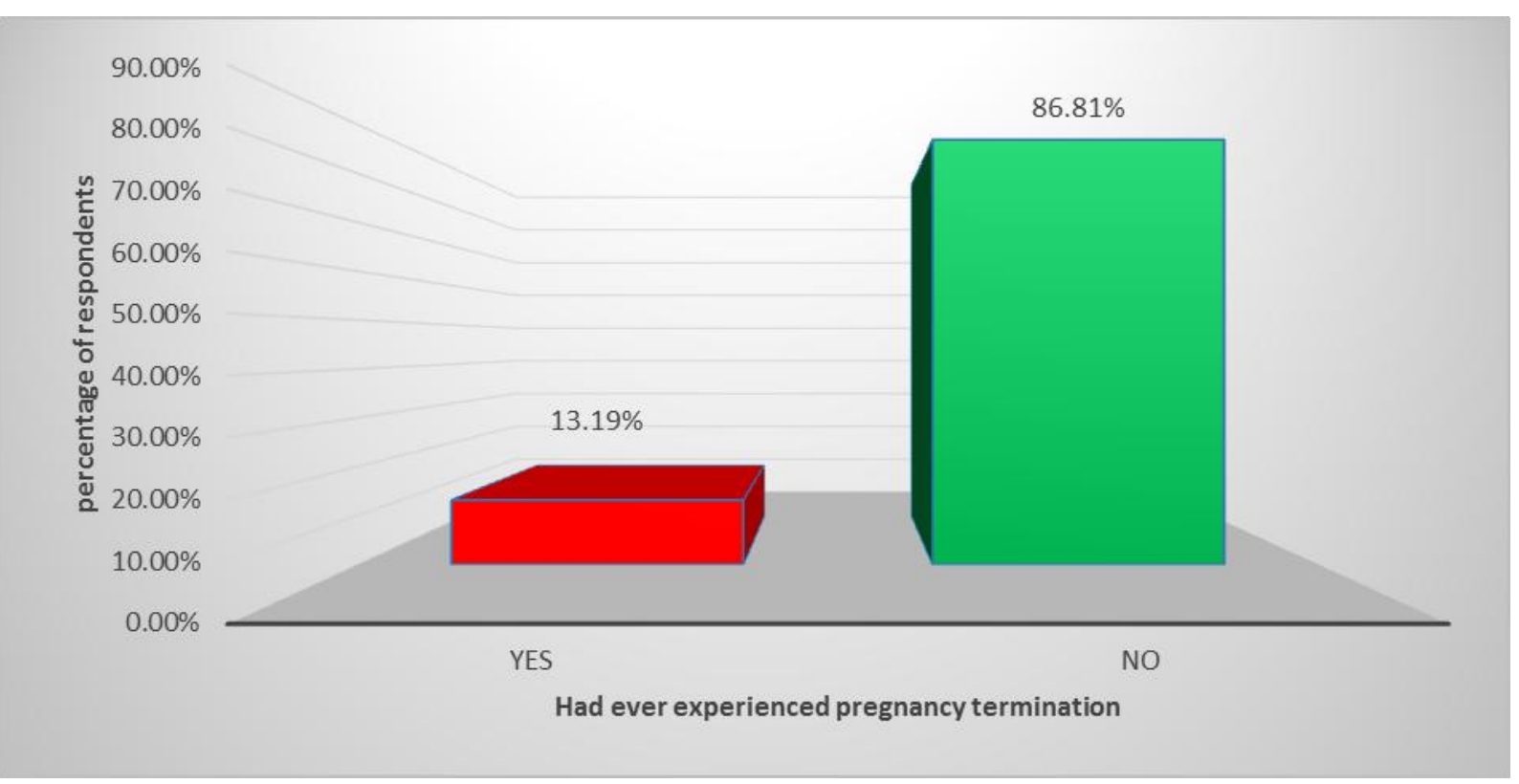

Fig. 1: Bar chart of responses of the respondents to had ever experienced pregnancy termination

\section{RESULTS}

Table 2: Results of the models before and after different resampling techniques

\begin{tabular}{|c|c|c|c|c|c|c|}
\hline P & Models & Accuracy (\%) & Sensitivity (\%) & Specificity (\%) & Precision (\%) & TN (\%) \\
\hline 90\% Train & Model to the raw data & 86.89 & 0 & 100 & 0 & 86.89 \\
\cline { 2 - 7 } & Model after undersampling & 59.05 & 59.83 & 58.94 & 18.01 & 90.67 \\
\cline { 2 - 7 } & Model after 'SMOTE’ & 74.53 & 50.00 & 79.38 & 32.43 & 88.92 \\
\cline { 2 - 7 } & Model after Oversampling & 59.17 & 58.09 & 59.33 & 17.72 & 90.37 \\
\cline { 2 - 7 } No = 21537. \\
Yes = 3270 & Model after both sampling & 59.17 & 58.09 & 59.32 & 17.72 & 90.37 \\
\hline
\end{tabular}

Table 2 presents the results of the model's accuracy, sensitivity, specificity, precision and True Negative predictive values. The ratio of training to testing data is $90: 10$. That's $90 \%$ of the data were used to model the data and $10 \%$ for testing the model's predictive accuracy and sensitivity. Logistic regression was fitted to the data without resampling technique (that is, "model to the raw data"); the model's accuracy is $86.89 \%$, Sensitivity is $0 \%$, Specificity is $100 \%$ while the Precision value is $0 \%$ and True Negative predictive value is $86.89 \%$. Note that the accuracy of the model is very high but misleading. This is because the model predicts all those with no experience of terminated pregnancy correctly but wrongly predicts those who experienced pregnancy termination as "NO". Among all the corrective measures, the Synthetic Minority Oversampling Technique (SMOTE) improved the model best, as the model's sensitivity and precision values increase significantly while keeping the accuracy of the model high.

Table 3: Results of the logistic regression

\begin{tabular}{|c|c|c|c|c|c|c|}
\hline \multicolumn{2}{|c|}{ Explanatory var. } & odds & Est. & SE & Z & P-value \\
\hline & Cons. & 0.1520 & -1.884 & 0.09155 & -20.579 & $<0.001$ \\
\hline & age & 1.0358 & 0.03518 & 0.00168 & 20.984 & $<0.001$ \\
\hline & afb & 0.9868 & -0.0133 & 0.00344 & -3.86 & $<0.001$ \\
\hline resid & urb & 1.5002 & 0.40557 & 0.03078 & 13.175 & $<0.001$ \\
\hline \multirow{4}{*}{ region } & NE & 1.8351 & 0.60708 & 0.04927 & 12.321 & $<0.001$ \\
\cline { 2 - 7 } & NW & 1.2246 & 0.20259 & 0.04867 & 4.163 & $<0.001$ \\
\cline { 2 - 7 } & SE & 1.4316 & 0.35882 & 0.05544 & 6.472 & $<0.001$ \\
\cline { 2 - 7 } & SS & 1.2531 & 0.2256 & 0.05256 & 4.292 & $<0.001$ \\
\cline { 2 - 7 } wealth & SW & 1.2594 & 0.23063 & 0.05163 & 4.467 & $<0.001$ \\
\hline \multirow{4}{*}{ edu } & mid & 1.0927 & 0.08861 & 0.03941 & 2.249 & 0.02454 \\
\cline { 2 - 7 } & ric & 0.9843 & -0.0159 & 0.03765 & -0.422 & 0.67336 \\
\cline { 2 - 7 } & pry & 1.3923 & 0.33094 & 0.0387 & 8.552 & $<0.001$ \\
\cline { 2 - 7 } & Sec & 1.5011 & 0.40618 & 0.03951 & 10.28 & $<0.001$ \\
\hline
\end{tabular}

Table 3 presents the output (results) of the logistic regression after synthetically oversampling the minority class. The sociodemographic factors that are significantly associated with having terminated pregnancy are age, age at first birth (AFB), residential area (resid), region, an education level (Edu) of women in their reproductive age. 


\section{DISCUSSION}

This study adds to the limited body of literature that investigates associated sociodemographic factors to terminated pregnancy. The odds of having terminated pregnancy increase for Nigerian women with every one year increase in age. A similar study of Ghanaian and Indian women observed that older women were more likely to have ever terminated a pregnancy (Dankwah et al., 2018). "It is possible that older women are more likely to terminate a pregnancy once they have achieved their desired family size" (Dankwah et al., 2018).

Nigerian women with primary, secondary and higher education levels are more likely to have pregnancy terminated than their counterparts with no formal education; this finding is consistent with studies by Dankwah et al., (2018); Yaya et al., (2018); Dickson et al., (2018); Adjei et al., (2015), Mote et al., (2010) and Sundaram et al., (2012). This might reflect the improved ability of women with various levels of education to navigate the health system and access pregnancy termination services. Women with no formal education might have limited access to such services and/or under-report attempts to induce abortion via more traditional methods (i.e., outside of formal healthcare settings). However, Dankwah et al., (2018) reported that education at the post-secondary level was not significantly related to having terminated pregnancy in contrast to similar studies (Arambepola et al., 2016; Fusco, 2013). Policies designed to improve access to and use of family planning methods for women with education to prevent unintended pregnancy may be a key implication of this finding. Past investigations that investigated the connections between education level and termination of pregnancy have shown mixed results. While a few studies confirmed that a woman's education level is identified with her choice to terminated pregnancy (Sihvo et al., 2003), others did not find a significant association (Elu, 2011).

Studies investigating the association between financial status and pregnancy termination demonstrate mixed results. The odds of having terminated pregnancy was greater for women of low socioeconomic status (Fusco, 2013; Yaya et al., 2018); in contrast, the likelihood of pregnancy termination is higher for women of high socioeconomic status in a study of Indian women (Elu, 2011). In some other studies, the authors report no significant relationship between financial situation and pregnancy termination (Sihvo et al., 2003). The findings presented here show that the odds of having terminated pregnancy is insignificant between the rich and the poor.

Bola (2016) suggested that pregnancy termination experience was higher among Southern women than Northern women. However, there was no breakdown to each geo-political zone (region). The results here show that the association between region and pregnancy termination is significant. Women from the NE, NW, SE, SS and SW have higher Odds of pregnancy termination than women from the North Central (NC).

Previous works had not considered women's age at first birth (AFB) as a factor influencing pregnancy termination. This is one of the contributions of the article. These results show a significant relationship between 'afb' and pregnancy termination. Obviously, the odds of having terminated pregnancy decrease for Nigerian women with every one year increase in age at first birth. This suggests that younger women (possibly unmarried) were more likely to have terminated pregnancy as a result of unwanted pregnancy.

\section{CONCLUSION AND RECOMMENDATION}

Based on the analysis of NDHS2013 data, this study found that the dataset is an imbalance, which affected logistic regression's performance. Hence, in modeling such data, there is a need to evaluate the model's accuracy, sensitivity and precision in order to ascertain the reliability of the model's results. Moreover, the socio-demographic factors such as regions, education status, financial status, age of the respondents as well as age at first birth were found significantly associated with terminated pregnancy.

Therefore, family planning projects in Nigeria should do more to educate and encourage the use of modern preventative techniques across the regions and all levels of education as well as a financial status to further reduce the cases of pregnancy termination. Above all, there is a need to improve maternal healthcare services to help women during the challenges of unintended pregnancy.

More factors affecting the prevalence of terminated pregnancy is a subject for further study. Regional variation needs to be addressed through appropriate legitimate and policy strategies to advance reproductive wellbeing in society.

\section{Funding Information}

This study is not funded by any organization/agency.

\section{Conflict of Interest}

The author declares no conflict of interest.

\section{REFERENCES}

Adjei G, Enuameh Y, Asante KP. (2015) Predictors of abortions in rural Ghana: a cross-sectional study. BMC Public Health; 15(1):202.

Appiah-Agyekum, N.N. (2014). Abortions in Ghana: experiences of university students. Health Science Journal, 8(4):531-540. 
Arambepola C, Rajapaksa LC and Attygalle D. (2016). Relationship of family formation characteristics with unsafe abortion: is it confounded by women's socio-economic status? A case control study from Sri Lanka. Reprod Health; 13(1):75.

Bola S.L. (2016). Spousal violence and pregnancy termination among married women in Nigeria. Afri Health Sci; 16(2): 429-440. http://dx.doi.org/10.4314/ahs.v16i2.11

Dankwah E., Megan Steeves, Dana Ramsay, Cindy Feng and Marwa Farag. (2018). The relationship between sociodemographic factors and reporting having terminated a pregnancy among Ghanaian women: a population-based study, International Health, page 1-7; doi:10.1093/inthealth/ihy035

Dickson K.S, Adde K.S. and Ahinkorah B.O. (2018). Socio-economic determinants of abortion among women in Mozambique and Ghana: evidence from demographic and health survey. Archives of Public Health, 76:37 https://doi.org/10.1186/s13690018-0286-0

Elul B. (2011). Determinants of induced abortion: an analysis of individual, household and contextual factors in Rajasthan, India. J Bio soc. Sci., 43(1):1- 17.

Fusco CLB. (2013). Unsafe abortion: a serious public health issue in a poverty stricken population. Reprod Climat; $28(1): 2-9$.

Ganatra, B., Gerdts, C., Rossier, C., Johnson Jr, B.R., Tuncalp, Ö, Assifi, A., Sedgh, G., Singh, S., Bankole, A., Popinchalk, A., Bearak, J., Kang, Z. \& Alkema, L. (2017). Global, regional, and subregional classification of abortions by safety, 2010-14: estimates from a Bayesian hierarchical model. The Lancet, 390:2372-2378.

Lunardon, G.M, and Nicola T. (2014). ROSE: a Package for Binary Imbalanced Learning. R Journal, 6(1), 82-92.

Kuhn, M., Wing, J., Weston, S., Williams, A., Chris Keefer, Allan Engelhardt, Tony Cooper, Zachary Mayer, Brenton Kenkel, the R Core Team, Michael Benesty, Reynald Lescarbeau, Andrew Ziem, Luca Scrucca, Yuan Tang, Can Candan and Tyler Hunt. (2018). caret: Classification and Regression Training. R package version 6.0-81. https://CRAN.R-project.org/package=caret

Mote CV, Otupiri E, Hindin MJ. (2010). Factors associated with induced abortion among women in Hohoe, Ghana. Afr J Reprod Health;14(4):115-21.

National Population Commission (NPC) [Nigeria] and ICF International. 2014. Nigeria Demographic and Health Survey 2013. Abuja, Nigeria, and Rockville, Maryland, USA: NPC and ICF International.

Ordinioha B, Owhonda G. (2008)) Clandestine abortion in Port Harcourt: Users' profile and motivation. Niger J Med. 17:33-36

R Core Team (2018). R: A language and environment for statistical computing. R Foundation for Statistical Computing, Vienna, Austria. URL https://www.R-project.org/.

Singh, S., Remez, L., Sedgh, G., Kwok, L. \& Onda, T. (2017). Abortion Worldwide 2017: Uneven Progress and Unequal Access. New York: Guttmacher Institute.

Sihvo S, Bajos N and Ducot B. (2003). Women's life cycle and abortion decision in unintended pregnancies. J Epidemiol Commun Health; 57(8):601-5.

Sundaram A, Juarez F and Bankole A. (2012). Factors associated with abortion-seeking and obtaining a safe abortion in Ghana. Stud Fam Plann; 43(4):273-86.

World Health Organization (Who). (2018). Preventing unsafe abortion. http://www.who.int/en/newsroom/factsheets/detail/preventing-unsafe-abortion [4 June 2018]

Yaya S, Amouzou A, Uthman O.A, et al. (2018). Prevalence and determinants of terminated and unintended pregnancies among married women: analysis of pooled cross-sectional surveys in Nigeria. BMJ Glob Health; 3:e000707. doi:10.1136/ bmjgh2018-000707 